\title{
Measuring liquidity risk in Social Security using VaR technique
}

\author{
Mohammad Khodaei Valahzaghard ${ }^{\mathrm{a}^{*}}$ and Gholamreza Tizfahmfard
}

\begin{abstract}
${ }^{a}$ Assist. Prof. \& Faculty Member, Department of Accounting, School of Management and Human Sciences, Tehran North Branch, Islamic Azad University (IAU), Tehran, Iran

${ }^{b}$ M.Sc. Student, Department of Management, School of Management and Human Sciences, Tehran North Branch, Islamic Azad University (IAU), Tehran, Iran

CHRON I CLE A B TRACT

Article history:

Received October 15, 2012

Received in revised format

4 December 2012

Accepted 8 December 2012

Available online

December 92012

Keywords:

Liquidity

$\mathrm{VaR}$

Simulation

Social security
\end{abstract}

\section{Introduction}

Measuring liquidity risk plays an important role on any business unit especially financial organizations. Social security systems in most countries around the world are responsible to provide necessary requirements in many countries such as health care, pension plans, etc. During the past few years, there have been tremendous efforts on measuring risk using value at risk (VaR) techniques. Ourir and Snoussi (2012) investigated the impact of negligence of dependency in liquidity extreme risk assessment of Tunisian stock market. They used returns dependency to evaluate market risk based on Time series-Extreme Value Theory combination. They compared VaRs estimated under independency relatively to the VaR when dependence was considered. The efficiency of those methods was examined and compared using the backtesting tests. They reported the adequacy of the recent extensions of liquidity risk in the VaR estimation and proved a performance improvement of

Corresponding author. Tel: +98-912-3443139

E-mail: m_khodaei@iau-tnb.ac.ir (M. Khodaei Valahzaghard)

(C) 2013 Growing Science Ltd. All rights reserved.

doi: $10.5267 /$ j.msl.2012.12.010 
VaR estimates under the assumption of dependency across a significant reduction of the estimation error, particularly with AR (1)-GARCH (1,1)-GPD model.

Brana et al. (2012) studied the impact of global excess liquidity on commodities and asset prices for a set of emerging market countries by investigating a panel VAR framework. They defined first global liquidity and reported that excess liquidity at global level had spillover impacts on output and price levels in emerging countries. According to their investigation, the effect on real estate, commodity and share prices in emerging countries was less clear.

Bracke and Fidora (2012) reported that (US) monetary policy shocks could explain the largest part of the variation in imbalances and financial market prices. They also reported that savings shocks and investment shocks could explain less of the variation. Niu et al. (2012) developed an improved portfolio optimization framework by developing the endogenous and exogenous liquidity risk and the corresponding indexes were designed to compute the endogenous/exogenous liquidity risk, respectively.

Härdle et al. (2012) modeled the dynamics of ask and bid curves in a limit order book market based on a dynamic semiparametric factor model. The shape of the curves was captured by a factor structure, which is estimated nonparametrically. Chadha et al. (2010) decomposed broad money into primitive demand and supply shocks and reported that supply shocks had played an important role in the time series in each of the USA, UK and Eurozone in the short to medium term.

\section{The proposed study}

The proposed model of this paper uses value at risk $(\mathrm{VaR})$ to measure the risk of liquidity. There are literally two methods for measuring VaR, which are simulation based method and parametric method and the proposed model of this paper uses simulation based method. In this method, we use historical data to predict future value. VaR describes the maximum loss on portfolio associated with assets for a specified period of daily, weekly or monthly. More specifically, according to $\mathrm{VaR}$, we are $X$ percent sure that the loss will not exceed more than a specified value, $V$. In other words, $V$ is the actual value of, which is subject to risk including two parameters of time horizon $(N)$ and level of confidence $(X)$. Fig. 1 shows details of VaR.

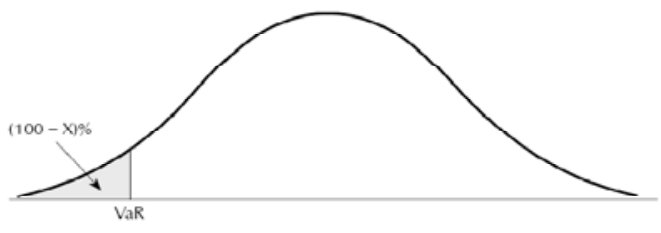

Fig. 1. Characteristics of VaR

In this method, analysts normally consider $\mathrm{N}=1$ since there are limited number of observations,

$\operatorname{VaR}$ in one day period $=\operatorname{VaR} \sqrt{N}$

When daily information changes are normally distributed with mean of zero, Eq (1) is precisely correct, otherwise, this formula is approximately correct. This ratio provides a number, which incorporates all associated risk components and a manager can make appropriate decision based on this value. This value also helps to design appropriate budget and different monitoring agencies such as Federal Reserve or insurance firms could determine risk associated with a budget. For instance, if we are about to measure risk for 292 business days, we can consider the following information,

\begin{tabular}{lllllllll}
\hline Day & 0 & 1 & 2 & 3 & $\ldots$ & 290 & 291 & 292 \\
\hline liquidity & 123.36 & 124.70 & 124.19 & 121.61 & & 75.29 & 79.99 & 128.11 \\
\hline
\end{tabular}


Let $v_{i}$ be liquidity in day $i$ and $m$ be the number of days where statistics are observed. Therefore, the liquidity can be predicted by $v_{m} \times v_{i} / v_{i-1}$. In our survey, we have collected daily information of liquidity over the period 2008-2011. Table 1 demonstrates details of our statistical observation in terms of min, median, standard deviation, skewness and Kurtosis.

Table 1

Statistical observations of liquidity

\begin{tabular}{|c|c|c|c|c|}
\hline Statistics & 2008 & 2009 & 2010 & 2011 \\
\hline Mean & 220.26 & 272.911 & 306.49 & 338.02 \\
\hline Median & 182.42 & 230.36 & 269.60 & 296.349 \\
\hline Standard deviation & 123.76 & 155.13 & 201.25 & 251.64 \\
\hline Rang & 946.11 & 1185.16 & 1475.65 & 1325.39 \\
\hline Skewness & 2.59 & 2.427 & 1.65 & 1.32 \\
\hline Kurtosis & 8.91 & 8.13 & 5.35 & 2.70 \\
\hline
\end{tabular}

\section{The results}

Based on the results of Table 1, the means of liquidity were in different range from 220.26 to 338.02 . Skewness of the time series seemed to be more than normal and details of time series can be verified in Fig. 1 to Fig. 4.

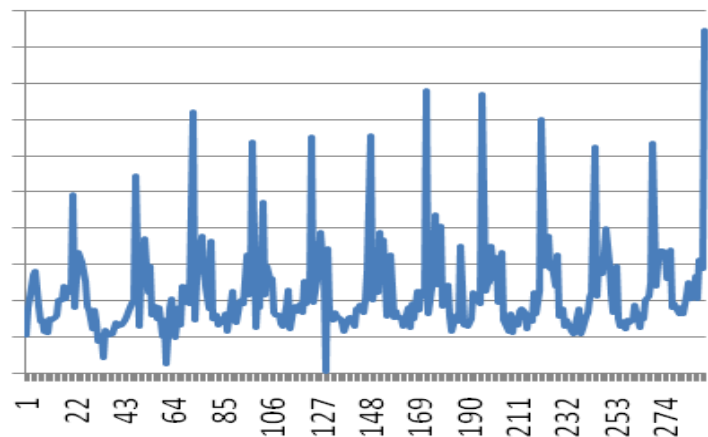

Fig. 1. Liquidity change for 274 days in 2008

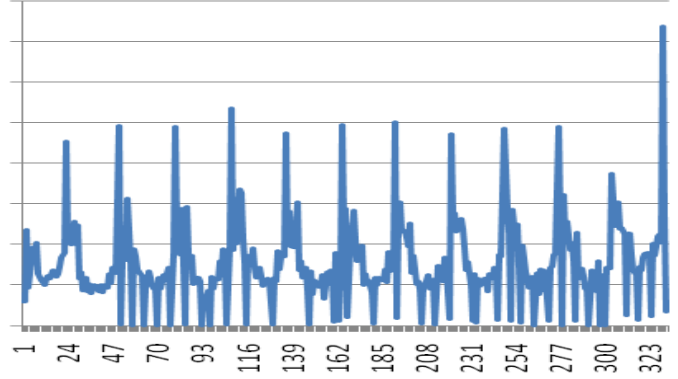

Fig. 3. Liquidity change for 323 days in 2010

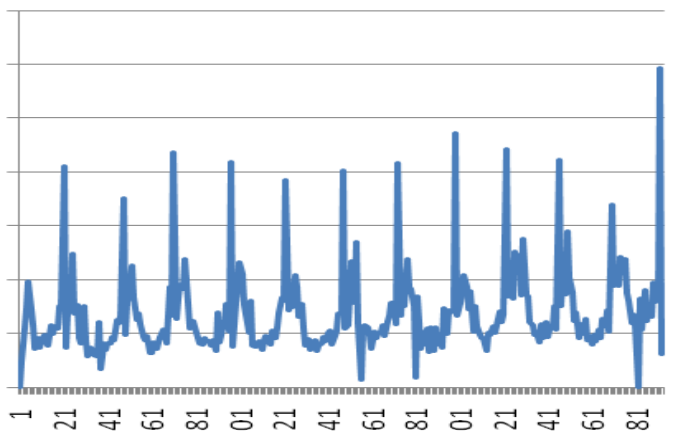

Fig. 2. Liquidity change for 281 days in 2009

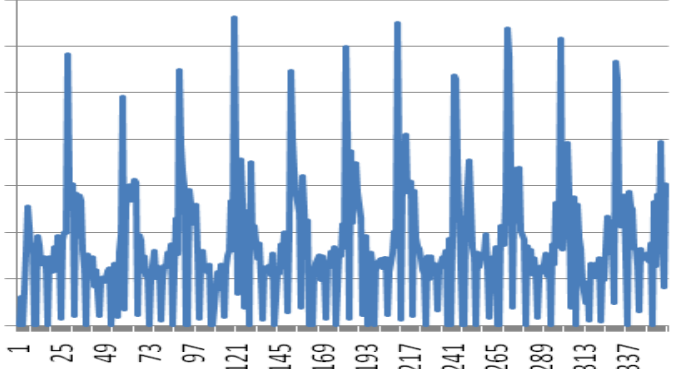

Fig. 4. Liquidity change for 337 days in 2011

In addition, Fig. 5 shows details of liquidity changes in 1235 working days.

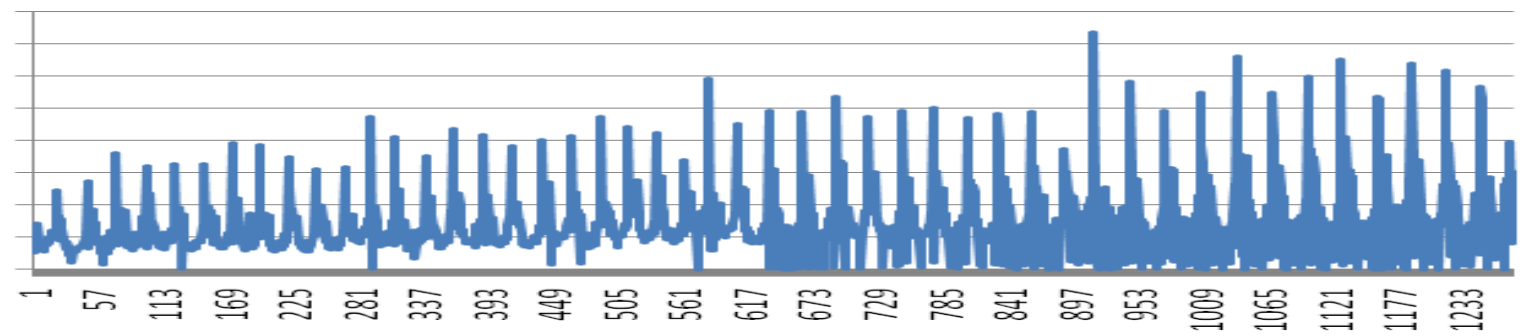

Fig. 4. Liquidity change for 1235 days

As explained earlier, we use 291 days of information using simulation technique to estimate VaR for the social security organization of Iran. Since there are 290 different observations, we have 290 
scenarios to study the first year. Similarly, we have 292 scenarios for 2008, 332 scenarios for 2009, 331 scenarios for 2010 and 358 scenarios for 2011, respectively. In this study, the confidence level is $95 \%$, therefore, VaR can be calculated as follows,

$$
\mu-1.64 \frac{\delta}{\sqrt{n}},
$$

where $\mu$ is the mean of liquidity of social security resulted from different scenario and $\sigma$ is the standard deviation of different observations and Table 2 demonstrates some basic statistics.

Table 2

Basic statistics

\begin{tabular}{lcccc}
\hline Statistics & 2008 & 2009 & 2010 & 2011 \\
\hline Mean & -483.45 & -1193 & 66050 & -1375738 \\
Median & -22.99 & -239 & -664473 & -595604 \\
Standard deviation & 1470 & 3044 & 1203491 & -295604 \\
Rang & 14662 & 30458 & 12154084 & 32155324 \\
Skewness & -5.02 & -5.03 & -5.227 & -5.355 \\
Kurtosis & 34.96 & 35.13 & 38.30 & 40.437 \\
\hline
\end{tabular}

As we can observe from the results of Table 2, mean of VaR has been changed significantly in different years. Fig. 6 to Fig. 9 demonstrate details of price change in these years.

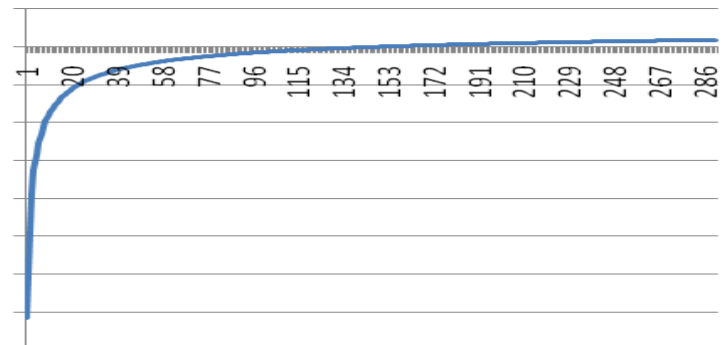

Fig. 6. VaR change for 274 days in 2008

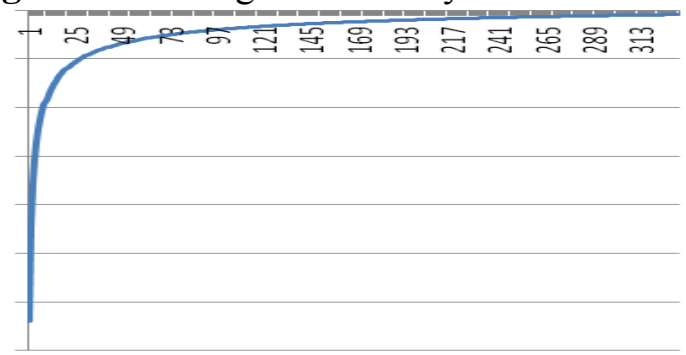

Fig. 8. VaR change for 323 days in 2010

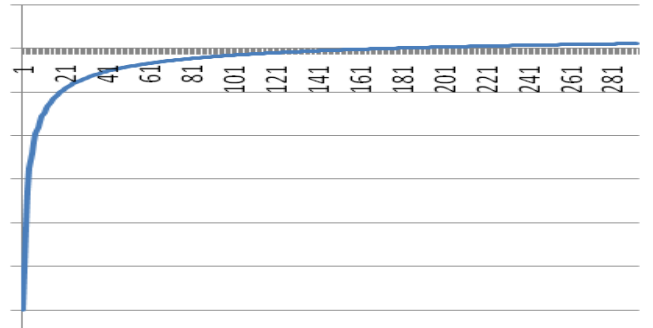

Fig. 7. VaR change for 281 days in 2009

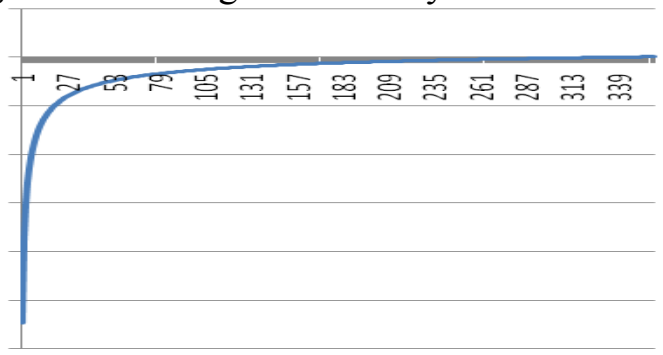

Fig. 9. VaR change for 337 days in 2011

The proposed study of this paper considers whether there is any change in VaR as the time goes on. In other words, the main hypothesis of this paper is to know whether VaR increases over the time. In order to test this hypothesis, we have divided the information into two groups of the first and second groups in each four year. Table 3 shows details of our findings for two groups.

\section{Table 3}

The results of comparing VaR in the first and the second group of each year

\begin{tabular}{lllllllll}
\hline & \multicolumn{4}{c}{ Mean difference } & \multicolumn{3}{c}{ Variance } & \multicolumn{2}{l}{ VaR } \\
\hline & Mean difference & P-value & Degree of freedom & t-student & Levon-F & Sig. & $1^{\text {st }}$ half & $2^{\text {nd }}$ half \\
\hline VaR & -927712.3 & 0.000 & 1273 & -10.964 & 190.506 & 0.000 & -1069807 & -142095 \\
\hline
\end{tabular}

As we can observe from the results of Table 3, the mean of $\mathrm{VaR}$ in the second half of the year is greater than the first half of the year. Therefore, we can confirm that VaR maintains an increasing trend over the time horizon. In order to compare VaR in different years, we have chosen ANOVA test and the results are presented in Table 4 as follows, 
Table 4

The results of ANOVA test

\begin{tabular}{llllllll}
\hline & Components & $\begin{array}{l}\text { Sum } \\
\text { Square }\end{array}$ & $\begin{array}{l}\text { Degree } \\
\text { freedom }\end{array}$ & $\begin{array}{l}\text { of } \\
\text { squares }\end{array}$ & of & F statistics & P-value \\
\hline VaR in & Between group & $4.5 \mathrm{E}+014$ & 3 & $1.490 \mathrm{E}+014$ & & \\
Social & Inside group & $2.8 \mathrm{E}+015$ & 1271 & $2.189 \mathrm{E}+012$ & 68.048 & 0.000 \\
Security & Total & $3.2 \mathrm{E}+015$ & 1274 & & & \\
\hline
\end{tabular}

According to the results of Table 4, there is a meaningful difference among the mean of all four groups. In other words, VaR was different in various years. In order to understand which years maintained big changes we have used Post Hoc Tests, Tukey HSD and LSD tests. The results have indicated that there was not any significant difference between mean of VaR in 2008 and 2009 but there was a meaningful difference in other years. There are also four sub-hypotheses associated with the proposed study of this paper, which are as follows,

\subsection{The first sub-hypothesis: Increasing trend in VaR in 2011}

The first sub-hypothesis of this paper is associated with an increasing trend in VaR during the year of 2011. We use the following regression analysis to test the results.

$$
L V a R=\beta_{0}+\beta_{1} t+\varepsilon,
$$

where LVAR is the logarithm of $\operatorname{VaR}, t$ is the time, $\beta_{0}$ and $\beta_{1}$ are coefficients, which are estimated using least square technique and $\varepsilon$ is the residual.

Table 5 shows details of implementing regression analysis for the data in this year.

\section{Table 5}

The results of VaR trend in Year 2011

\begin{tabular}{llllllll}
\hline Variable & Coefficient & $\begin{array}{l}\text { Standard } \\
\text { error }\end{array}$ & $\begin{array}{l}\text { Standard } \\
\text { coefficient }\end{array}$ & t-student & P-value & F-value & P-Value \\
\hline Intercept & 214.86 & 4.901 & & 43.84 & 0.000 & 222.09 & 0.000 \\
time & $2.53 \mathrm{E}-014$ & 0.000 & 0.619 & 14.90 & 0.000 & & \\
\hline
\end{tabular}

As we can observe from the results of Table 5, all t-student values are statistically meaningful. The positive coefficient of $\beta_{1}$ means as time increases $\mathrm{VaR}$ increases in this year. In addition, the high value of $\mathrm{F}$ statistics explains that the relationship is linear, indeed.

\subsection{The second sub-hypothesis: Increasing trend in VaR in 2010}

The first sub-hypothesis of this paper is associated with an increasing trend in VaR during the year of 2010. Again, we use Eq. (2) to fit the regression for year 2010. Table 6 shows details of implementing regression analysis for the data in this year.

\section{Table 6}

The results of VaR trend in Year 2010

\begin{tabular}{llllllll}
\hline Variable & Coefficient & $\begin{array}{l}\text { Standard } \\
\text { error }\end{array}$ & $\begin{array}{l}\text { Standard } \\
\text { coefficient }\end{array}$ & t-student & P-value & F-value & P-Value \\
\hline Intercept & 208.96 & 5.057 & & 41.32 & 0.000 & 210.29 & 0.000 \\
time & $4.98 \mathrm{E}-014$ & 0.000 & 0.624 & 14.50 & 0.000 & & \\
\hline
\end{tabular}

As we can observe from the results of Table 6, all t-student values are statistically meaningful. The positive coefficient of $\beta_{1}$ means as time increases $\mathrm{VaR}$ increases in this year. In addition, the high value of $\mathrm{F}$ statistics explains that the relationship is linear, indeed.

\subsection{The third sub-hypothesis: Increasing trend in VaR in 2009}

The first sub-hypothesis of this paper is associated with an increasing trend in VaR during the year of 2009. Again, we use Eq. (2) to fit the regression for year 2009. Table 7 shows details of implementing regression analysis for the data in this year. 
Table 7

The results of VaR trend in Year 2009

\begin{tabular}{llllllll}
\hline Variable & Coefficient & $\begin{array}{l}\text { Standard } \\
\text { error }\end{array}$ & $\begin{array}{l}\text { Standard } \\
\text { coefficient }\end{array}$ & t-student & P-value & F-value & P-Value \\
\hline Intercept & 167.96 & 4.131 & & 40.66 & 0.000 & 192.92 & 0.000 \\
time & $1.76 \mathrm{E}-011$ & 0.000 & 0.631 & 13.88 & 0.000 & & \\
\hline
\end{tabular}

As we can observe from the results of Table 7, all t-student values are statistically meaningful. The positive coefficient of $\beta_{1}$ means as time increases $\mathrm{VaR}$ increases in this year. In addition, the high value of $\mathrm{F}$ statistics explains that the relationship is linear, indeed.

\subsection{The fourth sub-hypothesis: Increasing trend in VaR in 2008}

The fourth sub-hypothesis of this paper is associated with an increasing trend in VaR during the year of 2008. Again, we use Eq. (2) to fit the regression for year 2008. Table 8 shows details of implementing regression analysis for the data in this year. As we can observe from the results of Table 8 , all t-student values are statistically meaningful. The positive coefficient of $\beta_{1}$ means as time increases $\mathrm{VaR}$ increases in this year. In addition, the high value of $\mathrm{F}$ statistics explains that the relationship is linear, indeed.

\section{Table 8}

The results of VaR trend in Year 2008

\begin{tabular}{llllllll}
\hline Variable & Coefficient & $\begin{array}{l}\text { Standard } \\
\text { error }\end{array}$ & $\begin{array}{l}\text { Standard } \\
\text { coefficient }\end{array}$ & t-student & P-value & F-value & P-Value \\
\hline Intercept & 163.49 & 4.033 & & 40.54 & 0.000 & 192.019 & 0.000 \\
time & $3.62 \mathrm{E}-011$ & 0.000 & 0.632 & 13.85 & 0.000 & & \\
\hline
\end{tabular}

\section{Conclusion}

In this paper, we have performed an empirical investigation to study liquidity risk in Iranian social security using VaR technique. The proposed model of this paper has gathered historical information for a fiscal year of 2008-2011. The study first divided the information of first and second half of each year into two groups and, using $\mathrm{VaR}$, technique analyzed whether there was any trend change in these two groups. The results of our survey have indicated that the mean of VaR in the second half of the year was greater than the first half of the year. Therefore, we could confirm that VaR maintains an increasing trend over the time horizon. We also studied the trend in liquidity using regression analysis for each year, separately and the results of our survey confirmed that there was an increasing trend in liquidity over time.

\section{References}

Bracke, T., \& Fidora, M. (2012). The macro-financial factors behind the crisis: Global liquidity glut or global savings glut?. The North American Journal of Economics and Finance, 23(2), 185-202.

Brana, S., Djigbenou, M.L., \& Prat, S. (2012). Global excess liquidity and asset prices in emerging countries: A PVAR approach. Emerging Markets Review, 13(3), 256-267.

Chadha, J.S., Corrado, L., \& Sun, Q. (2010). Money and liquidity effects: Separating demand from supply. Journal of Economic Dynamics and Control, 34(9), 1732-1747

Härdle, W.K., Hautsch, N., \& Mihoci, A. (2012). Modelling and forecasting liquidity supply using semiparametric factor dynamics. Journal of Empirical Finance, 19(4), 610-625

Niu, B., Fan, Y., Xiao, H., \& Xue, B. (2012). Bacterial foraging based approaches to portfolio optimization with liquidity risk. Neurocomputing, 98(3), 90-100

Ourir, A., \& Snoussi, W. (2012). Markets liquidity risk under extremal dependence: Analysis with VaRs methods. Economic Modelling, 29(5), 1830-1836. 